Donato Volkers Moutinho ${ }^{1}$

Sueli Gandolfi Dallari²

\title{
FINANCIAMENTO DO DIREITO À SAÚDE E NOVO REGIME FISCAL: A INCONSTITUCIONALIDADE DO ARTIGO 110 DO ATO DAS DISPOSIÇÕES CONSTITUCIONAIS TRANSITÓRIAS
}

Public health funding and new tax regime: The unconstitutionality of article 110 of the Brazilian Transitional Constitutional Provisions Act

\footnotetext{
${ }^{1}$ Faculdade de Direito da Universidade de São Paulo. São Paulo/SP, Brasil.

${ }^{2}$ Faculdade de Saúde Pública da Universidade de São Paulo. São Paulo/SP, Brasil.

Correspondência: Donato Volkers Moutinho.E-mail: donatovolkers@gmail.com
}

Recebido: 30/05/2018. Revisão: 04/12/2018. Aprovado: 15/01/2019. 


\section{RESUMO}

A saúde é uma necessidade pública, que exige a atuação concreta do Estado e movimenta sua atividade financeira. Logo, os serviços públicos de saúde são impactados pelas normas de Direito Financeiro, que orientam a distribuição de recursos. Nesse campo, o artigo 110 do Ato das Disposições Constitucionais Transitórias ainda merece análise detida. Este trabalho tem o objetivo de preencher essa lacuna ao avaliar a constitucionalidade do referido artigo. Com base no marco teórico apoiado na doutrina de direitos humanos, sociais e fundamentais, lança mão de dados empíricos para avaliar se os efeitos que o artigo 110 deve irradiar sobre o direito à saúde condizem com a Constituição de 1988. Como resultado, percebeu-se que o direito à saúde é um direito humano social fundamental, cujos níveis de eficácia e efetividade não podem sofrer retrocesso por qualquer medida adotada por entes federados. Observou-se que o esforço fiscal do Estado brasileiro para prover os serviços de saúde pública a sua população está aquém de sua capacidade econômica, e o referido artigo, quando permite a redução desse esforço, passa ao largo das obrigações assumidas pelo país e promove retrocesso na saúde pública e na fruição do direito à saúde. Conclui-se que o artigo 110 do Ato das Disposições Constitucionais Transitórias é inconstitucional, que, para evitar retrocesso no direito à saúde, o Supremo Tribunal Federal deve suspender a sua eficácia e declarar essa inconstitucionalidade e que o Estado brasileiro precisa se planejar para, progressivamente, elevar seu patamar de despesas no setor.

\section{Palavras-Chave}

Direito Financeiro; Direito Sanitário; Novo Regime Fiscal; Saúde Pública; Sistema Único de Saúde.

\section{ABSTRACT}

Health is a public need that requires the concrete action of the State and mobilizes its financial activity. Therefore, the public health services are impacted by public finance law, which rules the distribution of resources. In this field, the Article 110 of the Brazilian Transitional Constitutional Provisions Act still deserves close analysis. The objective of this paper is to fill this gap by evaluating the constitutionality of said article. Within a theoretical framework based on the doctrine of human, social and fundamental rights, it uses empirical data to assess whether the effects of article 110 that should probably radiate on the right to health are consistent with the Brazilian Constitution of 1988. As a result, the realization was achieved that the right to health is a fundamental social human right, whose level of effectiveness cannot be regressed by any measure adopted by federated entities. It was observed that the Brazilian State fiscal effort, to provide public health services to the population, is beneath its economic capacity; and when the referred article allows for the reduction of this effort, it neglects the obligations assumed by the country and promotes deterioration of both public health and the fulfillment of the right to health. The conclusion reached is that Article 110 of the Brazilian Transitional Constitutional Provisions Act is unconstitutional, and in order to avoid regression, the Brazilian Supreme Court should suspend its effects and declare its unconstitutionality, and that the Brazilian State should plan to progressively raise the level of expenses in the sector.

\section{Keywords}

Brazilian National Health System; Brazilian New Fiscal Regime; Health Law; Public Finance; Public Finance Law; Public Health. 


\section{Introdução}

A Organização Mundial da Saúde (OMS) põe a ausência de doença lado a lado com a influência das condições de vida e do ambiente de trabalho nas definições de saúde ${ }^{1}$. Assim, na medida em que se percebe e se reconhece que o ambiente influi de forma decisiva nas condições de saúde dos indivíduos, é necessário admitir que cada pessoa não é a única responsável por seu estado de saúde 2 .

Os processos de industrialização e urbanização levaram operários e empresários a viverem próximos. Então, aqueles passaram a almejar e reivindicar padrão de vida semelhante ao destes, enquanto estes perceberam tanto que a produtividade de suas linhas de produção exigia operários saudáveis, quanto que poderiam ser contaminados pelas doenças que eventualmente atingissem seus empregados ${ }^{3}$.

Esse foi o momento em que se reconheceu a saúde da população como uma necessidade pública, exigindo a atuação concreta do Estado, movimentando sua atividade financeira e tornando-se relevante para o ramo do direito que a estuda, qual seja, o Direito Financeiro 4 . Nesse contexto, as escolhas políticas de alocação de recursos para fazer frente às necessidades públicas conduzem à instituição de normas constitucionais e infraconstitucionais de Direito Financeiro, com efeitos sobre o volume de recursos direcionados a cada atividade estatal.

Como exemplo de dispositivo que afeta - quase determina - a quantidade de recursos que serão direcionados à saúde pública, o artigo 110 do Ato das Disposições Constitucionais Transitórias (ADCT), transcrito a seguir, ainda carece de uma análise mais detida da doutrina jurídica nacional, inclusive quanto a sua constitucionalidade. Tendo em vista essa lacuna, o objetivo deste trabalho é verificar se o artigo 110 do ADCT é constitucional.

Art. 110. Na vigência do Novo Regime Fiscal, as aplicações mínimas em ações e serviços públicos de saúde e em manutenção e desenvolvimento do ensino equivalerão:

I - no exercício de 2017, às aplicações mínimas calculadas nos termos do inciso I do $\$ 2^{\circ}$ do art. 198 e do caput do art. 212, da Constituição Federal; e

${ }^{1}$ WORLD HEALTH ORGANIZATION. Constitution (1946). Disponivel em: <http://apps.who.int/gb/bd/PDF/ bd47/EN/constitution-en.pdf>. Acesso em: 23 maio 2018.

2DALLARI, Sueli Gandolfi. Poderes republicanos e a defesa do direito à saúde: evolução da proteção do direito à saúde nas constituições do Brasil. In: ALVES, Sandra M. C.; DELDUQUE, Maria C.; DINO NETO, Nicolao. Direito sanitário em perspectiva. Brasília-DF: Escola Superior do Ministério Público da União, 2012. v. 2, p. 27.

${ }^{3}$ DALLARI, Sueli Gandolfi. Uma nova disciplina: o direito sanitário. Revista de Saúde Pública, São Paulo, v. 22 , n. 4, p. 329, 1988. Disponivel em: <http://www.scielo.br/pdf/rsp/v22n4/08.pdf>. http://dx.doi. org/10.1590/S0034-89101988000400008.

${ }^{4}$ CONTI, José Mauricio. O planejamento orçamentário da administração pública no Brasil. 2017. 556 p. Tese (Professor Titular) - Departamento de Direito Econômico, Financeiro e Tributário, Faculdade de Direito, Universidade de São Paulo, São Paulo, 2017. p. 27. 
II - nos exercícios posteriores, aos valores calculados para as aplicações mínimas do exercício imediatamente anterior, corrigidos na forma estabelecida pelo inciso II do $\$ 1^{\circ}$ do art. 107 deste Ato das Disposições Constitucionais Transitórias 5 .

Com essa finalidade, este trabalho examina a doutrina jurídica e as normas internas e internacionais relacionadas a direitos humanos, direitos sociais e direitos fundamentais, a fim de verificar qual é a extensão das garantias reconhecidas ao direito à saúde. Adiante, trata dos princípios, das diretrizes organizacionais e da gestão do Sistema Único de Saúde (SUS). Em seguida, passa à análise das normas que regulam o financiamento do direito à saúde no Brasil, sem esquivar-se de observar o patamar de recursos que o Estado brasileiro direciona às ações e aos serviços públicos de saúde. Finalmente, dedica-se a avaliar os efeitos que irradiarão do novo regime fiscal (NRF), especificamente do artigo 110 do $\mathrm{ADCT}$, sobre o direito à saúde.

\section{Saúde: um direito humano social fundamental}

$\mathrm{Na}$ Declaração Universal dos Direitos Humanos (DUDH) ${ }^{6}$, artigo 25, a comunidade internacional reconheceu que todo ser humano tem direito a um padrão de vida capaz de lhe assegurar, entre a satisfação de outras necessidades, saúde e bem-estar, inclusive os cuidados médicos indispensáveis. Portanto, o direito à saúde foi arrolado naqueles direitos humanos ditos universais, cuja satisfação requer, como indica o preâmbulo da DUDH, a adoção de medidas progressivas de caráter nacional e internacional, com o objetivo de assegurar seu reconhecimento e sua observância universal e efetiva.

Com o Pacto Internacional dos Direitos Econômicos, Sociais e Culturais (Pidesc), a promoção da saúde - um desses direitos - figurou claramente como obrigação dos Estados-Partes. No artigo 12, eles reconheceram "[...] o direito de todos ao gozo do mais alto padrão possível de saúde física e mental"7 e se comprometeram à adoção das medidas necessárias para alcançarem a plena realização desse direito.

Influenciada pela ordem internacional, a Constituição da República Federativa do Brasil de 1988 (CF/1988), em seu artigo 6º , positivou o direito à saúde entre os direitos sociais. Ademais, no início do caput de seu artigo 196, estabeleceu

\footnotetext{
${ }^{5}$ BRASIL. Constituição da República Federativa do Brasil de 1988. Disponível em: <http://www.planalto.gov. br/ccivil_03/Constituicao/Constituicao.htm>. Acesso em: 22 mar. 2019.

${ }^{6}$ UNITED NATIONS. Resolution n. 217 (III), 10 December 1948. International Bill of Human Rights. A. Universal Declaration of Human Rights. Paris. Disponivel em: <http://www.un.org/ga/search/view_doc. asp?symbol=A/RES/217(III)\&Lang=E >. Acesso em: 23 maio 2018.

${ }^{7}$ UNITED NATIONS. General Assembly. International Covenant on Economic, Social and Cultural Rights. Adopted and opened for signature, ratification and accession by Resolution n. 2.200 (XXI), of 16 December 1966. Disponivel em: <http://www.ohchr.org/EN/Professionallnterest/Pages/CESCR.aspx>. Acesso em: 23 maio 2018.
} 
que "a saúde é direito de todos e dever do Estado [...]"8. Portanto, no Brasil, a saúde é reconhecida como um direito de todas as pessoas, sendo que a responsabilidade pela adoção das medidas necessárias a sua efetivação cabe ao Estado.

Deve-se ressaltar que, além de positivado entre os direitos sociais, o direito à saúde foi alçado à condição de um direito fundamental na ordem constitucional brasileira. Logo, acumula a condição de direito humano - enquanto posição jurídica reconhecida na esfera do direito internacional positivo ao ser humano como tal - e de direito fundamental social - enquanto positivado como tal na CF/1988.

O Pidesc - incorporado à ordem interna via Decreto n. $591 / 1992^{9}$ - preconizou a necessidade de postura ativa dos Estados-Partes, que devem adotar as medidas necessárias à plena realização do direito à saúde, conforme dispõe seu artigo 12, inciso 2. Por conseguinte, no Brasil, o direito à saúde está entre os direitos fundamentais sociais chamados prestacionais (positivos), que "[...] têm por objeto prestações do Estado [...] diretamente vinculadas à criação, destinação, distribuição e redistribuição de serviços e bens materiais que se aponta, com propriedade, para sua dimensão economicamente relevante"10, como ensina Ingo Sarlet.

Embora não se possa desconsiderar que, em última análise, todos os direitos dependem de prestações materiais do Estado para sua garantia e, portanto, têm custos $^{11}$, é preciso reconhecer que os direitos prestacionais, como o direito à saúde, na medida em que exigem a implementação de políticas públicas, com expressivo emprego de recursos humanos e materiais, para sua efetiva realização, dependem do dispêndio de relevantes quantias de recursos públicos e estão mais sujeitos à capacidade econômica estatal. Nesse sentido, como aponta Sarlet ${ }^{12}$, sua eficácia e efetivação depende, em alguma medida, da conjuntura econômica, tendo a limitação de recursos como limite fático. Atento a esse limite fático, o Pidesc, conforme leitura combinada de seus artigos $2^{\circ}$ e 12 , ao exigir do Brasil, enquanto Estado-Parte, a adoção das medidas que se façam necessárias para assegurar o direito de todos desfrutarem o mais elevado nível possível de saúde, o exige tão somente no limite de seus recursos disponíveis, podendo os meios apropriados serem garantidos progressivamente.

\footnotetext{
${ }^{8}$ BRASIL. Constituição da República Federativa do Brasil de 1988, cit.

${ }^{9}$ BRASIL. Decreto n. 591, de 06 de julho de 1992. Atos Internacionais. Pacto Internacional sobre Direitos Econômicos, Sociais e Culturais. Promulgação. Disponível em: <http://www.planalto.gov.br/ccivil_03/ decreto/1990-1994/d0591.htm>. Acesso em: 22 jan. 2019.

${ }^{10}$ SARLET, Ingo W. Os direitos fundamentais sociais na Constituição de 1988. In: PIOVESAN, Flávia; GARCIA, Maria (Orgs.). Direitos econômicos, sociais, culturais e ambientais. São Paulo: Revista dos Tribunais, 2008. p. 655. (Coleção doutrinas essenciais - direitos humanos; v. 3).

${ }^{11}$ HOLMES, Stephen; SUNSTEIN, Cass R. The cost of rights: why liberty depends on taxes. New York: W. W. Norton \& Company, 1999.

${ }^{12}$ SARLET, Ingo W. Os direitos fundamentais sociais na Constituição de 1988, op. cit., p. 655-656.
} 


\section{É que, como explica Élida Graziane Pinto,}

Porque não são passíveis de terem "solução" de uma única vez e de uma vez por todas, as políticas públicas de natureza prestacional (como o são saúde, educação, assistência social etc.) são tidas como de eficácia constitucional progressiva ${ }^{13}$.

Por conseguinte, é indispensável que a sociedade, consciente da necessidade de satisfação progressiva do direito à saúde e dos demais direitos fundamentais sociais, participe dos processos orçamentários, tanto de planejamento quanto de execução, pois este é o fórum adequado para "[...] escolher a velocidade dos gastos sociais e proceder às escolhas viáveis dentro de um quadro de escassez de recursos"14, como observa Clémerson Clève.

Destarte, a progressividade na realização do direito à saúde é, por um lado, uma permissão - na medida em que não se exige sua satisfação plena e imediata e, por outro, uma exigência dos ordenamentos jurídicos internacional - enquanto direito humano - e interno - no qual se positivou sua condição de direito fundamental social. Logicamente, podem-se exigir do Estado as ações necessárias à realização progressiva do direito à saúde, vedada está a adoção de medidas que conduzam ao retrocesso em sua fruição.

Assim, para Sarlet, os direitos fundamentais sociais, em geral, e o direito à saúde, em particular, integram os elementos essenciais constitucionais, fazendo parte da própria identidade da $\mathrm{CF} / 1988$, de modo que devem ser considerados entre as "cláusulas pétreas" como "[...] autênticos limites materiais implícitos à reforma constitucional”15. Desse modo, sequer por meio de emendas à Constituição o Estado poderia adotar medidas que, na prática, imponham retrocessos à eficácia e à efetividade do direito à saúde. Essa interpretação condiz com o Pidesc, como esclarece o parágrafo 32 do Comentário Geral n. 14 do Comitê de Direitos Econômicos, Sociais e Culturais, a seguir:

32. Tal como acontece com todos os outros direitos no Pacto, há uma forte presunção de que medidas retrógradas tomadas em relação ao direito à saúde não são admissíveis. Se quaisquer medidas deliberadamente retrógradas forem tomadas, o Estado-parte tem o ônus de provar que elas foram introduzidas após a consideração mais cuidadosa de todas as alternativas e que elas são devidamente justificadas por referência à totalidade dos

\footnotetext{
${ }^{13}$ PINTO, Élida G. Financiamento dos direitos à saúde e à educação. São Paulo: Fórum, 2015. p. 45.

${ }^{14}$ CLĖVE, Clémerson Merlin. A eficácia dos direitos fundamentais sociais. In: PIOVESAN, Flávia; GARCIA, Maria. (Orgs.). Direitos econômicos, sociais, culturais e ambientais. São Paulo: Revista dos Tribunais, 2008. p. 249. (Coleção doutrinas essenciais - direitos humanos; v. 3).

${ }^{15}$ SARLET, Ingo W. Direitos sociais: o problema de sua proteção contra o poder de reforma na Constituição de 1988. In: PIOVESAN, Flávia; GARCIA, Maria. (Orgs.). Direitos econômicos, sociais, culturais e ambientais. São Paulo: Revista dos Tribunais, 2008. p. 757-758. (Coleção doutrinas essenciais - direitos humanos; v. 3).
} 
direitos previstos no Pacto no contexto da plena utilização dos recursos máximos disponíveis do Estado-Parte ${ }^{16}$.

Enquanto direito fundamental social, o direito à saúde tem eficácia vinculante que impõe que todos os atos normativos editados - inclusive emendas constitucionais -, caso colidam com seu conteúdo, sejam declarados inconstitucionais, sendo proibido, além da extinção, o retrocesso. Indo além, Pinto defende que a vedação do retrocesso na efetiva realização do direito à saúde, como a outra face do dever de progressividade, "[...] não se situa estritamente no patamar de vedação de extinção ou redução deliberada do arranjo, mas também inclui e exige a proibição de estagnação ou restrição interpretativa que lhe retire a possibilidade de progredir"17.

Pelo exposto, o direito à saúde é reconhecido nas ordens jurídicas internacionais e interna, respectivamente como um direito humano e um direito fundamental social. Em consequência, é responsabilidade do Estado brasileiro (tanto a União quanto os entes subnacionais) empreender as ações necessárias para, progressivamente - devendo avançar na velocidade que sua capacidade econômica permitir -, oferecer a todos o gozo do mais alto padrão possível de saúde física e mental. Desse modo, a adoção por ente federado de qualquer medida, normativa ou operacional, que conduza a retrocesso nos níveis de eficácia e efetividade do direito à saúde viola tanto a CF/1988 como o Pidesc, motivo pelo qual deve ser declarada inconstitucional.

\section{Serviços públicos de saúde}

Tendo consagrado a saúde como direito de todos e dever do Estado, a Assembleia Nacional Constituinte deixou registrada, no artigo 196 da CF/1988, a opção nacional pela universalidade no acesso às ações e aos serviços públicos de saúde. Como meio de concretizar essa opção, previu a criação de um "Sistema Único de Saúde", conforme seu artigo 198, caput e parágrafo $1^{\circ}$.

Além da universalidade, a CF/1988 estabeleceu a igualdade, a equidade e a integralidade como princípios fundamentais do SUS. Estabeleceu, ainda, como diretrizes organizativas do Sistema ${ }^{18}$, a descentralização, a direção única em cada esfera de governo, a participação da comunidade e a complementaridade do setor privado.

\footnotetext{
${ }^{16}$ UNITED NATIONS. United Nations Economic and Social Council. Committee on Economic, Social and Cultural Rights. Substantive issues arising in the implementation of the International Covenant on Economic, Social and Cultural Rights. General Comment $n$. 14 (2000). The right to the highest attainable standard of health (article 12 of the International Covenant on Economic, Social and Cultural Rights). Geneva, 25 Apr./12 May 2000. Disponível em: <http://tbinternet.ohchr.org/_layouts/treatybodyexternal/Download.aspx?symbolno $=\mathrm{E} \% 2 \mathrm{fC} .12 \% 2 \mathrm{f} 2000 \% 2 \mathrm{f} 4 \&$ Lang=en>. Acesso em: 23 maio 2018.

${ }^{17}$ PINTO, Élida G. Financiamento dos direitos à saúde e à educação, op. cit., p. 41.

${ }^{18} \mathrm{~A}$ respeito dos princípios fundamentais e das diretrizes organizativas do SUS, cf. AITH, Fernando M. A. Teoria geral do direito sanitário brasileiro. 2006. 458 f. Tese (Doutorado em Saúde Pública) - Programa de Pós-Graduação em Saúde Pública, Faculdade de Saúde Pública, Universidade de São Paulo, São Paulo, 2006. f. 393-398.
} 
Em 2016, os tribunais de contas de 25 estados e do Distrito Federal - a exceção foi Pernambuco -, numa iniciativa conjunta, avaliaram diversos aspectos da gestão de 4.466 municípios em sete setores de atuação do poder público. A gestão municipal da saúde foi a que alcançou a melhor avaliação nacional entre os setores fiscalizados.

Os mapas apresentados na Figura 1 ilustram os resultados gerais, à esquerda, e do setor de saúde, à direita, agregados por estado. Observa-se, no mapa à esquerda, que, no geral, a gestão municipal em termos gerais tem baixo nível de adequação e está em fase de adequação, a depender do estado onde os municípios se encontram. O mapa à direita, por seu turno, mostra que a gestão municipal da saúde é efetiva na maioria dos estados, sendo considerada muito efetiva nos estados do Amazonas, do Paraná e de Santa Catarina. Ao se compararem os dois mapas apresentados na Figura 1, fica patente que a situação na gestão municipal da saúde é bem superior ao quadro geral da administração municipal.

Apesar de ser mal avaliado por uma parcela dos cidadãos e de enfrentar uma série de obstáculos e desafios, o SUS possibilitou considerável ampliação do acesso aos serviços de saúde no país, como destacam Mario Scheffer e Fernando Aith ${ }^{19}$. Nesse sentido, como explicam Ana Viana, Luciana Lima e Maria Ferreira $^{20}$, graças à implantação e às políticas redistributivas do SUS, atualmente têm diminuído as distâncias que separam as regiões mais pobres daquelas economicamente mais fortes do Brasil, pelo menos no campo da saúde pública.

Portanto, percebe-se - certamente com a surpresa de muitos - que a gestão do sistema de saúde brasileiro funciona relativamente bem quando comparada a outras áreas da gestão pública no país, e que, desde 1988, foram muitos os avanços obtidos no acesso à saúde. Se, por um lado, a relativa boa gestão e os resultados dela advindos são motivo para moderada comemoração, por outro, fica claro que novos e expressivos avanços em termos de ampliação do acesso e melhoria da qualidade dos serviços de saúde pública dificilmente serão alcançados somente com ganhos de produtividade, sem a injeção de novos recursos no SUS.

\footnotetext{
${ }^{19}$ SCHEFFER, Mario C.; AITH, Fernando Mussa. A. O sistema de saúde brasileiro. In: Martins, Milton de Arruda et al. (Orgs.). Clínica médica. São Paulo: Manole, 2016. v. 1, p. 365.

${ }^{20}$ VIANA, Ana L. D’Ávila; LIMA, Luciana D. de; FERREIRA, Maria P. Condicionantes estruturais da regionalização na saúde: tipologia dos Colegiados de Gestão Regional. Ciência e Saúde Coletiva, Rio de Janeiro, v. 15, n. 5, p. 2324-2325, 2010. Disponível em: <http://www.scielo.br/pdf/csc/v15n5/v15n5a07.pdf>. http://dx.doi. org/10.1590/S1413-81232010000500007.
} 

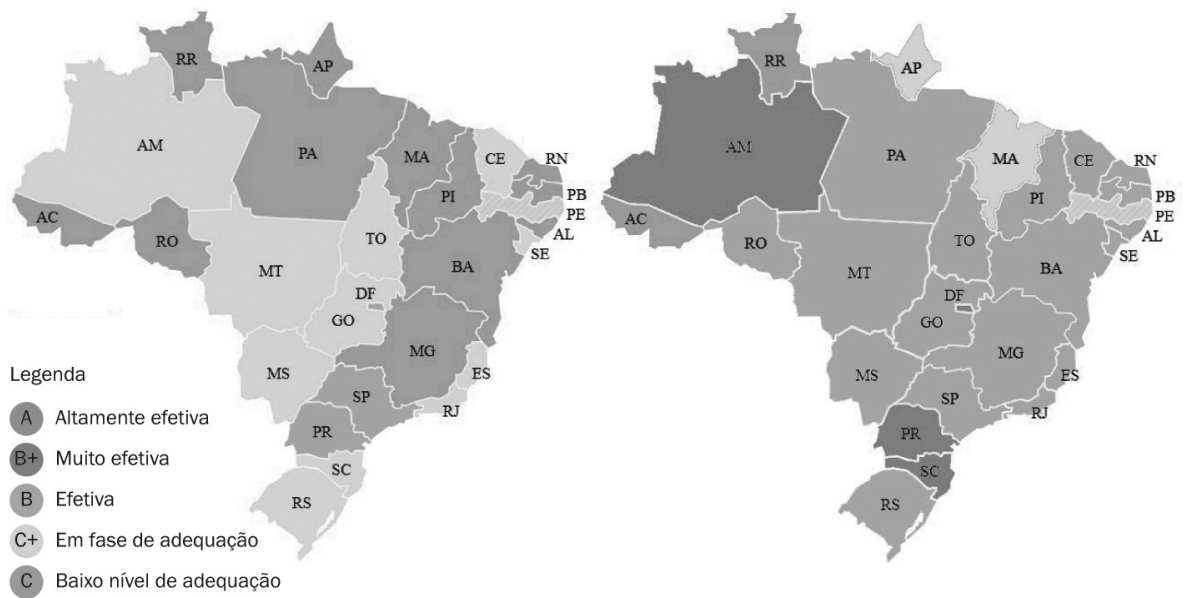

Mapa à esquerda: adaptado do Portal IEGM Brasil.

Mapa à direita: elaboração própria a partir dos dados do IEGM Brasil.

Fonte: Portal IEGM Brasil21.

Figura 1. Mapas do Índice de Efetividade da Gestão Municipal (IEGM) e do I-Saúde, em 2016.

\section{Financiamento dos serviços públicos de saúde}

Entre os anos de 1988 e 2000, a principal estratégia utilizada pelo constituinte originário para garantia de recursos a serem aplicados nas ações e nos serviços públicos de saúde foi vincular à seguridade a receita auferida por determinadas contribuições sociais. Todavia, diante das perdas de recursos e da instabilidade financeira sofridas pelo setor da saúde em decorrência da competição por recursos entre os três setores da seguridade, o reformador constituinte - sem abandonar a vinculação daqueles recursos que ainda restavam afetados à toda a seguridade resolveu, com a promulgação da Emenda à Constituição (EC) n. 29/2000²2, lançar mão, como nova e principal garantia de recursos, do instrumento de fixação de um valor mínimo de despesas a serem obrigatoriamente aplicadas anualmente às ações e aos serviços públicos de saúde. Quase 15 anos mais tarde, com a promulgação

\footnotetext{
${ }^{21}$ INSTITUTO RUI BARBOSA. Índice de efetividade da gestão municipal. Portal IEGM Brasil. Disponível em: <http://iegm.irbcontas.org.br/index.php>. Acesso em: 23 maio 2018.

${ }^{22}$ BRASIL. Emenda Constitucional n. 29, de 13 de setembro de 2000. Altera os arts. 34, 35, 156, 160, 167 e 198 da Constituição Federal e acrescenta artigo ao Ato das Disposições Constitucionais Transitórias, para assegurar os recursos mínimos para o financiamento das ações e serviços públicos de saúde. Disponível em: <http://www.planalto.gov.br/ccivil_03/constituicao/Emendas/Emc/emc29.htm>. Acesso em: 22 jan. 2019.
} 
da EC n. 86/2015 $5^{23}$, finalmente o valor mínimo a ser aplicado por todos os entes federados em ações e serviços públicos de saúde passou a ser calculado em função de sua receita - a exemplo do que já ocorria com a educação desde a promulgação da $\mathrm{CF} / 1988^{24}$, por força de seu artigo 212 , e com a saúde nos entes subnacionais desde a EC n. 29/2000.

Agora, considerando apenas as disposições contidas no texto permanente da CF/1988, conforme seu artigo 198, parágrafo 2 , inciso I, a União deveria, obrigatoriamente, aplicar em ações e serviços públicos de saúde, anualmente, pelo menos o valor equivalente a $15 \%$ de sua receita corrente líquida (RCL). Por sua vez, os estados e o Distrito Federal - naquelas receitas eminentemente estaduais -, e os municípios e o Distrito Federal - nas receitas de perfil municipal -, deveriam aplicar no setor pelo menos $12 \%$ e $15 \%$, respectivamente, do produto da arrecadação de determinados impostos e de certas receitas recebidas por transferências obrigatórias, por força do artigo 198, parágrafos $2^{\circ}$ e $3^{\circ}$, da CF/1988, combinados com os artigos $6^{\circ}$ a $8^{\circ}$ da Lei Complementar (LC) n. 141/2012 $2^{25}$.

Em decorrência, em 2017 a União despendeu R \$114,7 bilhões em ações e serviços públicos de saúde, equivalentes a $\mathrm{R} \$ 552,35$ per capita e correspondentes a $15,77 \%$ da RCL - superior ao mínimo de $15 \%$ da RCL. Por seu turno, os estados - considerados em conjunto - empenharam em 2017 um total de R\$ 89 bilhões em despesas com saúde pública, dos quais R $\$$ 65,6 bilhões com recursos próprios, consideráveis para fins de verificação das despesas mínimas obrigatórias em ações e serviços públicos de saúde, equivalentes a R \$320,63 per capita. Com isso, aplicaram em média $13,4 \%$ das receitas indicadas no artigo 198 , parágrafo $2^{\circ}$, inciso II, da $\mathrm{CF} / 1988$, ante o limite mínimo individual de $12 \%$ dessas entradas. Finalmente, os municípios - agrupados - executaram R\$141,8 bilhões em despesas na saúde, dos quais R \$ 82,5 bilhões com recursos próprios, ou R\$403,36 per capita, em 2017. Com isso, aplicaram em média $24,2 \%$ das receitas indicadas no artigo 198, parágrafo $2^{\circ}$, inciso III, da CF/1988, valor mais de $60 \%$ superior ao piso de $15 \%$.

\footnotetext{
${ }^{23}$ BRASIL. Emenda Constitucional n. 86, de 17 de março de 2015. Altera os arts. 165, 166 e 198 da Constituição Federal, para tornar obrigatória a execução da programação orçamentária que especifica. Disponível em: <http://www.planalto.gov.br/ccivil_03/Constituicao/Emendas/Emc/emc86.htm>. Acesso em: 22 jan. 2019.

${ }^{24}$ PINTO, Élida G.; FLEURY, Sônia. Custeio do direito à saúde: em busca da mesma proteção constitucional conquistada pelo direito à educação. Revista de Direito Sanitário, São Paulo, v. 12, n. 3, p. 54-80, mar./ jun. 2012. Disponível em: <http://www.revistas.usp.br/rdisan/article/view/55693/59109>. 10.11606/ issn.2316-9044.v13i1p54-80.

${ }^{25}$ BRASIL. Lei Complementar n. 141, de 13 de janeiro de 2012. Regulamenta o § 3o do art. 198 da Constituição Federal para dispor sobre os valores mínimos a serem aplicados anualmente pela União, Estados, Distrito Federal e Municípios em ações e serviços públicos de saúde; estabelece os critérios de rateio dos recursos de transferências para a saúde e as normas de fiscalização, avaliação e controle das despesas com saúde nas 3 (três) esferas de governo; revoga dispositivos das Leis nos 8.080, de 19 de setembro de 1990, e 8.689, de 27 de julho de 1993; e dá outras providências. Disponível em: <http:// www.planalto.gov.br/ccivil_03/leis/LCP/Lcp141.htm>. Acesso em: 22 jan. 2019.
} 
Assim, como apresenta o Gráfico 1, a União, que antes da implantação do SUS respondia por $70 \%$ do total de gastos públicos no setor ${ }^{26}$, foi a origem de $43,19 \%$ dos recursos aplicados em saúde no ano de 2017. No mesmo ano, os estados, o Distrito Federal e os municípios elevaram sua participação nas despesas, respectivamente, para $24,7 \%, 1,03 \%$ e $31,08 \%$ do total de recursos aplicados em ações e serviços públicos de saúde no país.

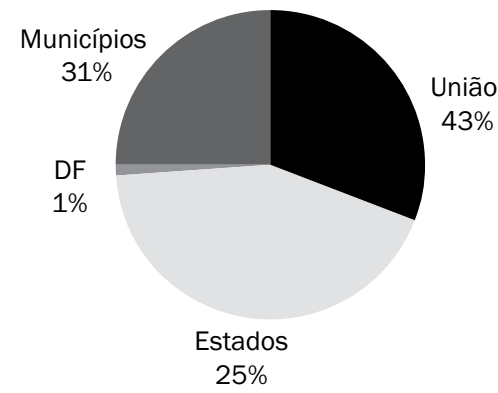

Fonte: BRASIL. Ministério da Saúde. DATASUS ${ }^{27}$.

Gráfico 1. Despesas com ações e serviços públicos de saúde por origem dos recursos

A redução da participação federal nos gastos governamentais totais em saúde no Brasil também é percebida quando comparadas as despesas dos entes federados à riqueza produzida no país. Segundo Sérgio Piola et al. ${ }^{28}$, em 2000 os gastos em ações e serviços públicos de saúde da União, dos estados e dos municípios, foram, respectivamente, de $1,73 \%, 0,54 \%$ e $0,6 \%$ do PIB. Desde então, enquanto a União manteve praticamente estável seu esforço econômico na saúde - em 2017, despendeu 1,75\% do PIB com ações e serviços públicos de saúde -, os estados e municípios direcionaram mais esforços para o setor, aplicando, respectivamente, $1 \%$ e 1,26\% de seu PIB em $2017^{29}$. Assim, o peso da ampliação dos gastos no período recaiu, principalmente, sobre os entes subnacionais.

\footnotetext{
${ }^{26}$ CONSELHO NACIONAL DE SECRETÁRIOS DE SAÚDE - CONASS. O financiamento da saúde. Brasília-DF: CONASS, 2011. p. 13. (Coleção para entender a gestão do SUS, 2). Disponível em: <http://www.conass. org.br/bibliotecav3/pdfs/colecao2011/livro_2.pdf>. Acesso em: 23 maio 2018.

${ }^{27}$ BRASIL. Ministério da Saúde. DATASUS. Sistema de Informações sobre Orçamentos Públicos em Saúde (SIOPS): Indicadores. Disponível em: <http://portalms.saude.gov.br/repasses-financeiros/siops/ indicadores>. Acesso em: 24 maio 2018.

${ }^{28} \mathrm{PIOLA}$, Sérgio F. et al. Financiamento público da saúde: uma história à procura de rumo. Rio de Janeiro: Instituto de Pesquisa Econômica Aplicada, 2013. p. 14-15. (Texto para discussão n. 1846).

${ }^{29}$ BRASIL. Banco Central do Brasil - BCB. Indicadores econômicos consolidados: I23 - Produto Interno Bruto e taxas médias de crescimento. Brasília-DF, 9 maio 2018. Disponível em: <http://www.bcb.gov.br/pec/ Indeco/Port/indeco.asp>. Acesso em 15 maio 2018.
} 
Sob outro ponto de vista, para avaliar se o Brasil, com o sistema de financiamento dos serviços públicos de saúde descritos ao longo deste tópico, tem empreendido as ações necessárias e na velocidade que permite sua capacidade econômica para oferecer à população o mais alto padrão possível de saúde, é essencial a comparação entre os gastos brasileiros no setor e aqueles realizados por outros países. Assim, na Tabela 1, os gastos públicos do governo brasileiro em saúde em 2015 são comparados com os observados em dez países desenvolvidos, agregados de acordo com o sistema de saúde pública adotado em cada nação. Na Tabela 2, por sua vez, a comparação é realizada com os demais dez países mais populosos da América Latina.

Scheffer e Aith $^{30}$ ensinam que os sistemas cujo financiamento é predominantemente público estão associados a uma maior igualdade de acesso e a melhores indicadores de saúde, enquanto aqueles com financiamento majoritariamente privado relacionam-se com as maiores desigualdades - tanto no acesso ao sistema quanto no estado de saúde da população -, além de apresentarem os gastos de saúde totais (públicos e privados) mais elevados. Ao mirar os países com sistema universal, percebe-se na Tabela 1 que em todos eles, à exceção do Brasil, o gasto público em saúde é superior ao privado. Aliás, com 42,75\% de participação pública em 2015, o Brasil é o único país do mundo, entre os que optaram pelo sistema universal de saúde, “[...] onde o gasto privado supera o público”31, como afirmam Maria Barros e Sérgio Piola.

Para avaliar o grau de prioridade que a saúde ostenta no conjunto dos gastos públicos, é importante comparar a participação dos gastos no setor com todos os gastos governamentais. Como se verifica na Tabela 1, em 2015 a saúde respondeu por apenas 7,66\% dos gastos governamentais brasileiros, enquanto a média dos dez países desenvolvidos selecionados foi de $17,77 \%$ - proporção $131,95 \%$ superior à nacional. Entre os países latino-americanos selecionados, conforme a Tabela 2, apenas a Venezuela teve participação dos gastos em saúde, no total de gastos públicos, inferior ao Brasil, sendo que a média desses países foi de $12,06 \%$, mais de $50 \%$ superior à nacional. Fica claro que gastar em saúde não é prioridade no orçamento governamental brasileiro.

Observe-se que, em 2015, os demais países de sistema universal apresentados na Tabela 1 tiveram, em média, um gasto público per capita de 4,45 vezes o do Brasil. O gasto público brasileiro com saúde, de US\$ 594,93 por habitante (Tabela 2 ), foi relevantemente inferior $(15,78 \%)$ até aos gastos dos países mais populosos da América Latina, onde o Brasil possui a maior economia. Não é razoável supor que um sistema de saúde que aplica poucos recursos por habitante oferecerá um atendimento de boa qualidade.

\footnotetext{
${ }^{30}$ SCHEFFER, Mario C.; AITH, Fernando Mussa. A. O sistema de saúde brasileiro, op. cit., v. 1, p. 356.

${ }^{31}$ BARROS, Maria E. D.; PIOLA, Sérgio F. O financiamento dos serviços de saúde no Brasil. In: MARQUES, Rosa M.; PIOLA, Sérgio F.; CARRILLO ROA, Alejandra. Sistemas de saúde no Brasil: organização e financiamento. Rio de Janeiro: Associação Brasileira de Economia da Saúde, 2016. p. 113. Disponível em: <http://abresbrasil. org.br/sites/default/files/livro_sistemas_de_saude_no_brasil.pdf>. Acesso em: 23 maio 2018.
} 
Tabela 1. Gasto público em saúde por país, de acordo com o sistema, em 2015.

\begin{tabular}{|c|c|c|c|c|}
\hline \multicolumn{5}{|c|}{ Gastos do governo geral em saúde 2015} \\
\hline \multicolumn{5}{|c|}{ Sistemas universais de saúde } \\
\hline País $^{1}$ & $\begin{array}{l}\text { Saúde }^{2} \\
(\%)\end{array}$ & $\begin{array}{c}\text { Políticas } \\
\text { públicas }^{3}(\%)\end{array}$ & $\begin{array}{c}\text { GGG total em } \\
\text { relação ao PIB (\%) }\end{array}$ & $\begin{array}{c}\text { Gasto per capita } \\
\text { (US\$) }\end{array}$ \\
\hline Brasil & 42,75 & 7,66 & 3,81 & 594,93 \\
\hline Canadá & 73,55 & 19,07 & 7,68 & $3.383,36$ \\
\hline Espanha & 71,03 & 14,88 & 6,51 & $2.260,53$ \\
\hline Inglaterra & 80,35 & 18,51 & 7,94 & $3.330,25$ \\
\hline Itália & 74,87 & 13,35 & 6,74 & $2.508,59$ \\
\hline Portugal & 66,22 & 12,30 & 5,94 & $1.762,31$ \\
\hline Média (fora o Brasil) & 73,20 & 15,62 & 6,96 & $2.649,01$ \\
\hline \multicolumn{5}{|c|}{ Sistemas de seguros sociais } \\
\hline País ${ }^{1}$ & $\begin{array}{l}\text { Saúde }{ }^{2} \\
(\%)\end{array}$ & $\begin{array}{c}\text { Públicas totais }{ }^{3} \\
\text { (\%) }\end{array}$ & $\begin{array}{c}\text { GGG total em } \\
\text { relação ao PIB (\%) }\end{array}$ & $\begin{array}{c}\text { Gasto per capita } \\
\text { (US\$) }\end{array}$ \\
\hline Alemanha & 84,47 & 21,42 & 9,42 & $4.524,91$ \\
\hline Áustria & 75,58 & 15,10 & 7,80 & $3.883,65$ \\
\hline França & 78,92 & 15,31 & 8,70 & $3.584,99$ \\
\hline Média & 79,66 & 17,28 & 8,64 & $3.997,85$ \\
\hline \multicolumn{5}{|c|}{ Sistemas liberais de saúde } \\
\hline País $^{1}$ & $\begin{array}{c}\text { Saúde }^{2} \\
(\%)\end{array}$ & $\begin{array}{c}\text { Públicas totais }{ }^{3} \\
(\%)\end{array}$ & $\begin{array}{c}\text { GGG total em } \\
\text { relação ao PIB (\%) }\end{array}$ & $\begin{array}{c}\text { Gasto per capita } \\
\text { (US\$) }\end{array}$ \\
\hline EUA & 50,36 & 22,57 & 8,48 & $4.801,94$ \\
\hline Suíça & 70,73 & 25,16 & 8,53 & $5.362,89$ \\
\hline Média & 60,55 & 23,87 & 8,51 & $5.082,41$ \\
\hline
\end{tabular}

${ }^{1}$ Países selecionados de acordo com o sistema ${ }^{32}$.

${ }^{2}$ Gastos do Governo Geral (GGG) com saúde em relação ao total gasto com saúde no país.

${ }^{3} \mathrm{GGG}$ com saúde em relação a todos os GGG no país.

Fonte: World Health Organization ${ }^{33}$.

Observe-se que, em 2015, os demais países de sistema universal apresentados na Tabela 1 tiveram, em média, um gasto público per capita de 4,45 vezes o do Brasil. O gasto público brasileiro com saúde, de US\$ 594,93 por habitante (Tabela 2), foi relevantemente inferior $(15,78 \%)$ até aos gastos dos países mais populosos da América Latina, onde o Brasil possui a maior economia. Não é razoável supor que um sistema de saúde que aplica poucos recursos por habitante oferecerá um atendimento de boa qualidade.

\footnotetext{
${ }^{32}$ SCHEFFER, Mario C.; AITH, Fernando Mussa. A. O sistema de saúde brasileiro, op. cit., v. 1, p. 356.

${ }^{33}$ WORLD HEALTH ORGANIZATION - WHO. Global Health Observatory data repository. Disponível em: <http:// apps.who.int/gho/data/node.main.HEALTHFINANCING?lang=en>. Acesso em: 15 maio 2018.
} 
Tabela 2. Gasto público em saúde, nos países mais populosos da América Latina, em 2015.

\begin{tabular}{lcccc}
\hline \multicolumn{5}{c}{ Gastos do governo geral em saúde em 2015 } \\
\hline País & $\begin{array}{c}\text { Saúde }^{\mathbf{1}} \\
\text { (\%) }\end{array}$ & $\begin{array}{c}\text { Públicos } \\
\text { totais }^{\mathbf{2}} \text { (\%) }\end{array}$ & $\begin{array}{c}\text { GGG total em } \\
\text { relação ao PIB } \\
\text { (\%) }\end{array}$ & $\begin{array}{c}\text { Gasto per } \\
\text { capita (US\$) }\end{array}$ \\
\hline Argentina & 71,42 & 12,34 & 4,88 & 992,58 \\
Bolívia & 68,01 & 9,79 & 4,36 & 303,23 \\
Brasil & $\mathbf{4 2 , 7 5}$ & $\mathbf{7 , 6 6}$ & $\mathbf{3 , 8 1}$ & $\mathbf{5 9 4 , 9 3}$ \\
Chile & 60,78 & 19,58 & 4,91 & $1.156,74$ \\
Colômbia & 66,78 & 12,19 & 4,13 & 569,48 \\
Cuba & 88,59 & & 9,62 & $2.195,94$ \\
Equador & 49,67 & 10,95 & 4,24 & 486,84 \\
Guatemala & 32,03 & 14,93 & 1,83 & 142,19 \\
México & 52,17 & 11,25 & 3,06 & 526,21 \\
Peru & 61,70 & 14,43 & 3,25 & 414,00 \\
Venezuela & 47,68 & 3,11 & 1,51 & 276,25 \\
\hline Média (fora o Brasil) & $\mathbf{5 9 , 8 8}$ & $\mathbf{1 2 , 0 6}$ & $\mathbf{4 , 1 8}$ & $\mathbf{7 0 6 , 3 5}$ \\
\hline
\end{tabular}

${ }^{1}$ Gastos do Governo Geral (GGG) com saúde em relação ao total gasto com saúde no país.

${ }^{2} \mathrm{GGG}$ com saúde em relação a todos os GGG no país.

Fonte: World Health Organization ${ }^{34}$.

Finalmente, a participação do gasto público brasileiro com saúde em relação ao PIB em 2015 foi de 3,81\%, porcentagem que é inferior à média dos demais países mais populosos da América Latina, que foi de 4,18\% do PIB (Tabela 2), e à dos países desenvolvidos selecionados que possuem sistemas universais de saúde aplicaram, 6,96\% do PIB (Tabela 1). Para ampliar a comparação, no mesmo ano o gasto público global em saúde equivaleu a 5,88\% do PIB mundial - em 2015, a soma dos gastos governamentais de saúde de todos os países foi de US $\$ 4,4$ trilhões, segundo a OMS, enquanto a soma do PIB desses países foi de US\$ 74,782 trilhões, de acordo com o Banco Mundial ${ }^{35}$.

Portanto, após verificar a relação entre os gastos governamentais brasileiros em saúde pública e seus gastos governamentais em todas as áreas, o PIB, o tamanho de sua população e o gasto privado em saúde no país, e comparar a razão obtida com a de outros países, conclui-se que o esforço fiscal que o Brasil faz para prover os serviços de saúde pública a sua população está claramente aquém de sua capacidade

\footnotetext{
${ }^{34}$ WORLD HEALTH ORGANIZATION - WHO. Global Health Observatory data repository, cit..

${ }^{35} \mathrm{XU}$, Ke et al. New perspectives on global health spending for universal health coverage: global report. Geneva: World Health Organization, 2018. (Working paper WHO/HIS/HGF/HF n. 18.2). Disponível em: <http://apps.who.int/iris/bitstream/handle/10665/259632/WHO-HIS-HGF-HFWorkingPaper-17.10-eng. pdf?sequence=1>. Acesso em: 23 maio 2018.
} 
econômica. Considerando que o PIB é uma razoável medida de sua capacidade econômica, pode-se supor que, se o Brasil pretende ter um sistema de saúde que oferte serviços públicos de boa qualidade, como determina a CF/1988 e como se obrigou perante a comunidade internacional, precisa se planejar para elevar progressivamente seu patamar de gastos no setor, de forma a, ao menos no longo prazo, ultrapassar o gasto público global com saúde em relação ao PIB (5,88\% em 2015) e se aproximar do padrão daqueles países desenvolvidos que mantêm sistemas de saúde universais.

\section{Novo regime fiscal (NRF)}

Em meio às crises econômica e política, o Governo Federal apresentou a Proposta de Emenda à Constituição (PEC) n. 241/2016 ${ }^{36}$, para, segundo sua exposição de motivos, estabilizar o crescimento da despesa primária e conter a expansão da dívida pública federal, com o objetivo de reverter seu quadro de desequilíbrio fiscal e retomar o crescimento da economia. Aprovada a proposta, o Congresso Nacional promulgou a EC n. 95/2016 $6^{37}$, instituindo, no âmbito da União, o novo regime fiscal, para vigorar por 20 anos, nos exercícios financeiros entre 2017 e 2036, conforme estabelece o novo artigo 106 do ADCT $^{38}$.

Em síntese, de acordo com o artigo 107 do $\mathrm{ADCT}^{39}$, o NRF tomou individualmente os valores de despesa primária pagos em 2016 - incluídos os "restos a pagar" referentes a exercícios anteriores - pelos poderes e órgãos autônomos federais e os estabeleceu - com poucas e taxativas exceções, previstas em seu parágrafo $6^{\circ}-$ como limites reais para as despesas a serem pagas entre 2017 e 2036. Até 2026, os limites serão corrigidos unicamente pela variação do Índice Nacional de Preços ao Consumidor Amplo (IPCA). No período posterior a 2026, o presidente da República poderá propor, uma vez por mandato e mediante projeto de lei complementar, a alteração do método de correção, conforme artigo 108, caput e parágrafo único, combinado com o artigo 109, parágrafo $1^{\circ}$, inciso II, do ADCT.

O NRF também alterou o regime das despesas mínimas obrigatórias a serem aplicadas pela União em ações e serviços públicos de saúde e na manutenção e no desenvolvimento do ensino. Nesse caso, de forma ligeiramente diferente, é o valor

\footnotetext{
${ }^{36}$ BRASIL. Câmara dos Deputados. Proposta de Emenda à Constituição n. 241-A, de 2016. Altera o Ato das Disposições Constitucionais Transitórias, para instituir o Novo Regime Fiscal, e dá outras providências.

Disponivel em: <http://www.camara.gov.br/proposicoesWeb/prop_mostrarintegra?codteor=1495741\&filena me=Tramitacao-PEC+241/2016>. Acesso em: 22 jan. 2019.

${ }^{37}$ BRASIL. Emenda Constitucional n. 95, de 15 de dezembro de 2016. Altera o Ato das Disposições Constitucionais Transitórias, para instituir o Novo Regime Fiscal, e dá outras providências. Disponível em: <http://www.planalto.gov.br/ccivil_03/constituicao/emendas/emc/emc95.htm>. Acesso em: 22 jan. 2019.

${ }^{38}$ BRASIL. Senado Federal. Art. 106 (ADCT). Disponível em: <https://www.senado.leg.br/atividade/const/ con1988/ADC1988_06.06.2017/art_106_.asp>. Acesso em: 22 jan. 2019.

${ }^{39}$ BRASIL. Senado Federal. Art. 107 (ADCT). Disponivel em: <http://www.senado.leg.br/atividade/const/ con1988/ADC1988_06.06.2017/art_107_.asp>. Acesso em: 22 jan. 2019.
} 
calculado - na forma do texto constitucional permanente - de aplicação mínima para 2017 - e não 2016, como previsto no limite imposto pelo artigo 107 do ADCT - que foi tomado como referência. Assim, por força do artigo 110 do ADCT, entre 2018 e 2036 o valor mínimo a ser obrigatoriamente despendido com ações e serviços públicos de saúde será igual a 15\% da RCL do exercício de 2017, atualizado conforme o IPCA.

Logo, como o valor da RCL da União foi de R $\$ 727,3$ bilhões $^{40}$ em 2017, o valor mínimo que o governo federal deverá obrigatoriamente aplicar anualmente em ações e serviços públicos de saúde, entre 2018 e 2036, é de R\$109,1 bilhões (em valores correntes de 2017).

Se o valor mínimo real absoluto permanecerá inalterado - congelado -, o valor mínimo per capita a ser aplicado pela União, ainda em valores correntes de 2017, em ações e serviços públicos de saúde cairá, em decorrência do crescimento populacional, de $\mathrm{R} \$ 525,32$, em 2017 , para $\mathrm{R} \$ 497,19$ e $\mathrm{R} \$ 480,74$, respectivamente em 2026 e $2036^{41}$. Portanto, o NRF provocará a redução da despesa mínima obrigatória por pessoa a ser aplicada em ações e serviços públicos de saúde.

Como medida do esforço econômico que o Estado faz para se desincumbir de sua responsabilidade de promover a saúde de todos, é importante verificar os efeitos do NRF na evolução dos gastos federais em relação à riqueza produzida no país. Em 2017, o valor mínimo a ser aplicado pela União em ações e serviços públicos de saúde, calculado conforme o artigo 198 , parágrafo $2^{\circ}$, inciso I, da CF/1988, equivaleu a 1,66\% do PIB. Em razão do disposto no artigo 110 do ADCT, o valor mínimo a ser aplicado pela União em ações e serviços públicos de saúde cairá anualmente, até chegar a $1,31 \%$ e $1,05 \%$ do PIB em 2026 e 2036, respectivamente (considerando que, para o ano de 2018, utilizou-se a estimativa de mercado de $2,7 \%$ para o $\mathrm{PIB}^{42}$. Para os anos entre 2019 e 2036, utilizaram-se as estimativas de crescimento anual de longo prazo previstas no projeto de Lei de Diretrizes Orçamentárias (LDO) para o ano de 2019, cuja média de variação estimada é de $2,41 \%$ ao ano $\left.{ }^{43}\right)$.

\footnotetext{
${ }^{40}$ BRASIL. Ministério da Fazenda. Secretaria do Tesouro Nacional - STN. Relatório resumido da execução orçamentária do Governo Federal e outros demonstrativos: dezembro de 2017. Brasília: STN, 2018. p. 13. Disponivel em: <http://www.tesouro.fazenda.gov.br/documents/10180/352657/RREOdez2017.pdf>. Acesso em: 23 maio 2018.

${ }^{41}$ De acordo com as estimativas e projeções populacionais do IBGE, a população brasileira era 207.660.929 habitantes em 2017 e será de 219.408 .552 e 226.917.266 habitantes, respectivamente, em 2026 e 2036. INSTITUTO BRASILEIRO DE GEOGRAFIA E ESTATíSTICA - IBGE. Projeção da População do Brasil por sexo e idade: 2000-2060. Disponível em: <https://ww2.ibge.gov.br/home/estatistica/populacao/ projecao_da_populacao/2013/default_tab.shtm>. Acesso em: 15 maio 2018.

${ }^{42}$ BRASIL. Banco Central do Brasil - BCB. Focus - Relatório de Mercado: 4 de maio de 2018. Brasília-DF: BCB, 2018. p. 2. Disponível em: <https://www.bcb.gov.br/pec/GCl/PORT/readout/R20180504.pdf>. Acesso em: 15 maio 2018.

${ }^{43}$ BRASIL. Congresso Nacional. Projeto de Lei n. 2/2018. Dispõe sobre as diretrizes para a elaboração e execução da Lei Orçamentária de 2019 e dá outras providências. p. 169. Disponível em: <http://www. camara.leg.br/internet/comissao/index/mista/orca/LDO/LD02019/proposta/CONSOLIDADO.pdf>. Acesso em: 23 maio 2018.
} 
Em relação à RCL - considerando, por simplificação, a manutenção da relação entre a RCL e o PIB e utilizando as estimativas de crescimento indicadas no parágrafo anterior -, por conta do artigo 110 do ADCT, o valor mínimo obrigatório de despesas da União em ações e serviços públicos de saúde vai cair de 15\%, em 2017 - quando ainda valeu a fórmula do artigo 198, parágrafo $2^{\circ}$, inciso I, da CF/1988 -, para 11,78\% e 9,51\% em 2026 e 2036, respectivamente,. Isso permitiria, em relação à regra prevista no texto permanente da Constituição, uma perda máxima acumulada pelo sistema de saúde de R $\$ 144,4$ bilhões até 2026 e de $\mathrm{R} \$ 627,8$ bilhões até 2036, em valores correntes de 2017.

Pode-se até argumentar, como justificativa para o artigo 110 do ADCT, que o Congresso Nacional, terá anualmente a opção de destinar mais recursos à saúde, via processo orçamentário. Porém, como alertam Fabiola Vieira e Rodrigo Benevides ${ }^{44}$, isso é pouco provável num cenário em que o "teto de gastos" imposto pela EC n. 95/2016 convive, por exemplo, com a explosão das necessidades de financiamento do Regime Geral de Previdência Social, que saltarão de 2,84\% do PIB, em 2019, para $6,01 \%$ do PIB, em $2036^{45}$. Logo, o NRF permitirá que a União reduza seu esforço econômico para oferecer saúde pública à população em relação aos últimos anos.

A União, apesar de ter reduzido consideravelmente sua participação nas despesas com ações e serviços públicos de saúde, é o principal financiador do sistema - conforme Gráfico 1, foi a origem de 43,19\% dos recursos aplicados no setor em 2017. Ademais, como apresentado, estados e municípios aplicam mais do que lhes é exigido pelo artigo 198 , parágrafos $2^{\circ}$ e $3^{\circ}$, da $\mathrm{CF} / 1988$, combinados com os artigos $6^{\circ}$ a $8^{\circ}$ da LC n. 141/2012. Desse modo, como asseveram Vieira e Benevides, os entes subnacionais não conseguirão absorver o impacto do congelamento de recursos federais, o que "[...] provocará grandes dificuldades para o financiamento do SUS [...]"46.

Para piorar as perspectivas sobre o futuro da qualidade dos serviços oferecidos pelo SUS, como alertam Vieira e Benevides, o envelhecimento da população, decorrente da ampliação da expectativa de vida e da redução da taxa de natalidade, pressionará o gasto público com saúde, na medida em que

\begin{abstract}
Mais pessoas idosas implicam maiores necessidades de acesso a serviços de saúde e a medicamentos [...]. Observa-se que o gasto médio do atendimento para pessoas entre 60 e 69 anos de idade foi $73 \%$ maior que o gasto para a faixa etária de 30 a 39 anos em $2015^{47}$.
\end{abstract}

\footnotetext{
${ }^{44}$ VIEIRA, Fabiola S.; BENEVIDES, Rodrigo P. de S. e. Os impactos do novo regime fiscal para o financiamento do sistema único de saúde e para a efetivação do direito à saúde no Brasil. Brasília-DF: Instituto de Pesquisa Econômica Aplicada, 2016. p. 8. (Nota técnica n. 28). Disponível em: <http://www.ipea.gov.br/ portal/images/stories/PDFs/nota_tecnica/160920_nt_28_disoc.pdf>. Acesso em: 23 maio 2018.

${ }^{45}$ BRASIL. Congresso Nacional. Projeto de Lei n. 2/2018, cit., p. 170.

${ }^{46}$ VIEIRA, Fabiola S.; BENEVIDES, Rodrigo P. de S. e. op. cit., p. 18.

${ }^{47}$ Id. Ibid., p. 19-20.
} 
Por conseguinte, ao mesmo tempo em que, como resultado do artigo 110 do ADCT, o país aplicará menos recursos no SUS, as necessidades de saúde da população crescerão.

O problema é ainda maior porque o esforço que o Brasil fez nos últimos anos para prover os serviços de saúde pública a sua população esteve claramente aquém de sua capacidade econômica, conforme apresentado na seção III deste artigo, demonstrando a necessidade de planejamento para que o país eleve progressivamente seu patamar de gastos no setor. Contudo, o caminho oposto foi adotado com a promulgação da EC n. 95/2016. Em consequência, segundo Vieira e Benevides ${ }^{48}$, podem-se esperar maiores dificuldades de acesso à saúde - especialmente para a população mais carente e nos estados mais pobres -, corte proporcionalmente maior nos programas preventivos, aumento da judicialização da saúde e prejuízo à economia nacional, em decorrência da perda do efeito multiplicador do gasto com saúde.

É necessário ressaltar, ainda, que os efeitos financeiros do artigo 110 do ADCT não se encerrarão com o término da vigência estipulada para a vigência do NRF, em 2036. Isso porque, após 19 anos congelado em R\$109,1 bilhões e com a restauração da compulsoriedade do artigo 198, parágrafo $2^{\circ}$, inciso I, da $\mathrm{CF} / 1988$, em tese o valor das despesas mínimas a serem obrigatoriamente aplicadas em ações e serviços públicos de saúde será de R \$ 175,0 bilhões em 2037 (em valores correntes de 2017 e utilizando as estimativas de crescimento indicadas anteriormente). Ora, certamente nem os mais fervorosos e otimistas defensores do SUS, pensando sensatamente, defenderão que a despesa com o sistema dê um salto de mais de $60 \%$ de um ano para o outro. O que provavelmente ocorreria, na melhor das hipóteses, seria a edição de nova EC para estabelecer uma regra de transição, ampliando o valor das perdas para o setor de saúde contabilizadas em razão do artigo 110 do ADCT.

Para o ministro Ricardo Lewandowski ${ }^{49}$, a garantia de financiamento estável e progressivo do SUS compõe a dimensão objetiva - ou institucional - do próprio direito à saúde. De fato, a restrição de recursos decorrente do artigo 110 do ADCT, inevitavelmente, causará a redução de acesso e cobertura no âmbito do SUS, afastando-o de suas finalidades e gerando retrocesso no direito humano social fundamental à saúde. Só que, como exposto, é inconstitucional qualquer medida, adotada por um ou mais entes federados, que conduza a retrocesso nos níveis de eficácia e efetividade do direito à saúde.

\footnotetext{
${ }^{48}$ VIEIRA, Fabiola S.; BENEVIDES, Rodrigo P. de S. e. op. cit.

${ }^{49}$ BRASIL. Supremo Tribunal Federal. Medida cautelar na ação direta de inconstitucionalidade n. 5.595 Distrito Federal. Relator: Ministro Ricardo Lewandowski. Decisão monocrática, Brasília-DF, 31 de agosto de 2017. Diário da Justiça Eletrônico, Brasília-DF, n. 198, p. 59-65, 4 set. 2017. Disponível em: <http://portal. stf.jus.br/processos/downloadPeca.asp?id=312629019\&ext=.pdf>. Acesso em: 23 maio 2018.
} 
Por isso é que Pinto reafirma que "[...] há um dever de progressividade no financiamento do SUS e que o princípio da vedação de retrocesso determina também ser vedada a estagnação fiscal do arranjo protetivo do direito à saúde" ${ }^{\text {"50 }}$. E, ao lado de Fábio Comparato et al. ${ }^{51}$, defende que, do ponto de vista constitucional, o gasto mínimo anual obrigatório em ações e serviços públicos de saúde - cuja progressividade seja garantida, pelo menos, de forma proporcional à receita - é inegociável e está para o direito à saúde assim como o habeas corpus está para o direito à liberdade de locomoção, de modo que não pode, validamente, sofrer restrição pelo legislador, nem mesmo o constituinte reformador.

Isto posto, o instrumento que exige a aplicação obrigatória de um determinado valor anual mínimo de despesas em ações e serviços públicos de saúde, na medida em que se constitui em garantia constitucional do direito à saúde - que não pode ser alvo de retrocesso -, deve ser progressivo, não podendo ser congelado ou reduzido, como faz a EC n. 95/2016.

O artigo 110 do ADCT, como demonstrado ao longo desta seção, provocará no âmbito da União - e, consequentemente, do Estado brasileiro - a redução da despesa mínima obrigatória per capita e da proporção das despesas em relação ao PIB e à RCL em ações e serviços públicos de saúde. Isso permite a redução de seu esforço econômico para financiar a saúde pública, passando ao largo das obrigações assumidas pelo país de empreender as ações necessárias para, progressivamente e na velocidade que sua capacidade econômica permite, oferecer à população o mais alto padrão possível de saúde física e mental. Inevitavelmente, tal dispositivo promove retrocesso na saúde pública e na fruição do direito à saúde, motivo pelo qual é inconstitucional.

Em tempo, foram ajuizadas no Supremo Tribunal Federal (STF) - e estão pendentes de julgamento, reunidas sob a relatoria da ministra Rosa Weber - quatro ações diretas de inconstitucionalidade (ADI) contra a EC n. 95/2016, a saber, as ADI n. 5.633, n. 5.643 , n. 5.658 e n. 5.680. Entre elas, a ADI n. 5.658 ataca severamente o artigo 110 do ADCT e requer tanto a declaração de sua inconstitucionalidade quanto a interpretação do artigo 107 do ADCT conforme a Constituição, para que o limite que ele impõe seja calculado e fiscalizado sem considerar as despesas com saúde e educação.

Assim, com o fim de evitar irrecuperável retrocesso no direito à saúde, o STF deve, o quanto antes, suspender a eficácia do artigo 110 do ADCT e declarar sua inconstitucionalidade.

\footnotetext{
${ }^{50}$ PINTO, Élida G. Financiamento dos direitos à saúde e à educação, op. cit., p. 220.

${ }^{51}$ COMPARATO, Fábio K. et al. Financiamento dos direitos à saúde e à educação: mínimos inegociáveis. Revista Consultor Jurídico, São Paulo, 27 jul. 2016. Disponível em: <https://www.conjur.com.br/2016jul-27/financiamento-direitos-saude-educacao-minimos-inegociaveis>. Acesso em: 23 maio 2018.
} 


\section{Conclusões}

Até 2036, o artigo 110 do ADCT provocará o seguinte impacto nas despesas mínimas obrigatórias da União em ações e serviços públicos de saúde, que garantem o financiamento do direito à saúde: (i) redução de $8,49 \%$ na despesa federal anual per capita, tendo como ponto de partida um gasto público nacional que já era, em $2015,77,54 \%$ e $15,78 \%$ inferior, respectivamente, aos gastos anuais per capita médios dos países desenvolvidos de sistema universal selecionados e dos demais dez países mais populosos da América Latina; (ii) redução na relevância em relação ao PIB, de 1,66\% para 1,05\%, em um cenário em que o Brasil aplicava em saúde pública somente $3,81 \%$ do PIB em 2015, contra o índice mundial de $5,88 \%$, a média de $4,18 \%$ do PIB nos vizinhos latino-americanos e a média de 6,96\% do PIB nos países desenvolvidos selecionados; (iii) redução de sua participação nas despesas totais de $15 \%$ para 9,51\% da RCL, sendo que, em 2015, os gastos governamentais médios dos dez países desenvolvidos selecionados e dos demais dez países mais populosos da América Latina eram, respectivamente, $131,95 \%$ e $57,48 \%$ superiores ao brasileiro; (iv) perda de $\mathrm{R} \$ 627,8$ bilhões, em valores correntes de 2017. Nesse período, em contraposição, as necessidades de saúde da população e, portanto, de seu financiamento, crescerão em razão do envelhecimento da população.

Como, conforme demonstrado, a gestão do SUS funciona relativamente bem quando comparada com outras áreas da gestão pública no país - inclusive foi o setor de atuação da gestão municipal mais bem avaliado em fiscalização realizada pelos tribunais de contas brasileiros -, o recurso que deixará de ser aplicado no sistema em decorrência do artigo 110 do ADCT não será compensado somente com ganhos de produtividade. Portanto, como consequência da inclusão do referido artigo na CF/1988, haverá retrocesso na saúde pública e nos níveis de eficácia e efetividade do direito à saúde.

Só que é responsabilidade do Estado brasileiro, decorrente do reconhecimento do direito à saúde como um direito humano social fundamental, empreender as ações necessárias para, progressivamente - devendo avançar na velocidade que sua capacidade econômica permitir -, possibilitar à população gozar do mais alto padrão possível de saúde física e mental. Assim, ao autorizar a redução do esforço econômico da União para financiar a saúde pública, passando ao largo das obrigações assumidas pelo país, o artigo 110 do ADCT causa retrocesso nos níveis de eficácia e efetividade do direito à saúde, e sua manutenção no sistema jurídico brasileiro viola tanto a CF/1988 como o Pidesc.

Pelo exposto e com vistas a evitar irrecuperável retrocesso no direito à saúde, o Supremo Tribunal Federal deve, o quanto antes, suspender a eficácia do artigo 110 do ADCT e declarar sua inconstitucionalidade. 
Adicionalmente, como o esforço fiscal que o Brasil faz para prover os serviços de saúde pública a sua população, conforme provado neste artigo, está claramente aquém de sua capacidade econômica, o Estado brasileiro precisa se planejar para elevar progressivamente seu patamar de gastos no setor, de forma a, ao menos no longo prazo, ultrapassar o gasto público global com saúde em relação ao PIB - que foi de 5,88\% em 2015 - e se aproximar do padrão daqueles países desenvolvidos que também optaram por manter sistemas de saúde universais.

\section{Referências}

AITH, Fernando M. A. Teoria geral do direito sanitário brasileiro. 2006. 458 f. Tese (Doutorado em Saúde Pública) - Programa de Pós-Graduação em Saúde Pública, Faculdade de Saúde Pública, Universidade de São Paulo, São Paulo, 2006.

BARROS, Maria E. D.; PIOLA, Sérgio F. O financiamento dos serviços de saúde no Brasil. In: MARQUES, Rosa M.; PIOLA, Sérgio F.; CARRILLO ROA, Alejandra. Sistemas de saúde no Brasil: organização e financiamento. Rio de Janeiro: Associação Brasileira de Economia da Saúde, 2016. p. 101-138. Disponível em: <http://abresbrasil.org.br/sites/default/files/ livro_sistemas_de_saude_no_brasil.pdf $>$. Acesso em: 23 maio 2018.

BRASIL. Banco Central do Brasil - BCB. Focus - Relatório de Mercado: 4 de maio de 2018. Brasília-DF: BCB, 2018. Disponível em: <https://www.bcb.gov.br/pec/GCI/PORT/readout/ R20180504.pdf>. Acesso em: 15 maio 2018.

Indicadores econômicos consolidados: I23 - Produto Interno Bruto e taxas médias de crescimento. Brasília-DF, 9 maio 2018. Disponível em: <http://www.bcb.gov.br/pec/Indeco/ Port/indeco.asp >. Acesso em 15 maio 2018.

BRASIL. Ministério da Fazenda. Secretaria do Tesouro Nacional - STN. Relatório resumido da execução orçamentária do Governo Federal e outros demonstrativos: dezembro de 2017. Brasília: STN, 2018. Disponível em: <http://www.tesouro.fazenda.gov.br/documents/10180/352657/ RREOdez2017.pdf>. Acesso em: 23 maio 2018.

Ministério da Saúde. DATASUS. Sistema de Informações sobre Orçamentos Públicos em Saúde (SIOPS): Indicadores. Disponível em: <http://portalms.saude.gov.br/repassesfinanceiros/siops/indicadores>. Acesso em: 24 maio 2018.

CLÈVE, Clémerson Merlin. A eficácia dos direitos fundamentais sociais. In: PIOVESAN, Flávia; GARCIA, Maria. (Orgs.). Direitos econômicos, sociais, culturais e ambientais. São Paulo: Revista dos Tribunais, 2008. p. 239-252. (Coleção doutrinas essenciais - direitos humanos; v. 3).

COMPARATO, Fábio K. et al. Financiamento dos direitos à saúde e à educação: mínimos inegociáveis. Revista Consultor Jurídico, São Paulo, 27 jul. 2016. Disponível em: <https://www. conjur.com.br/2016-jul-27/financiamento-direitos-saude-educacao-minimos-inegociaveis > Acesso em: 23 maio 2018. 
CONSELHO NACIONAL DE SECRETÁRIOS DE SAÚDE - CONASS. O financiamento da saúde. Brasília-DF: CONASS, 2011. (Coleção para entender a gestão do SUS, 2). Disponível em: <http://www.conass.org.br/bibliotecav3/pdfs/colecao2011/livro_2.pdf>. Acesso em: 23 maio 2018.

CONTI, José Mauricio. O planejamento orçamentário da administração pública no Brasil. 2017. 556 p. Tese (Professor Titular) - Departamento de Direito Econômico, Financeiro e Tributário, Faculdade de Direito, Universidade de São Paulo, São Paulo, 2017.

DALLARI, Sueli Gandolfi. Poderes republicanos e a defesa do direito à saúde: evolução da proteção do direito à saúde nas constituições do Brasil. In: ALVES, Sandra M. C.; DELDUQUE, Maria C.; DINO NETO, Nicolao. Direito sanitário em perspectiva. Brasília-DF: Escola Superior do Ministério Público da União, 2012. v. 2, p. 21-44.

. Uma nova disciplina: o direito sanitário. Revista de Saúde Pública, São Paulo, v. 22, n. 4, p. 327-334, 1988. Disponível em: <http://www.scielo.br/pdf/rsp/v22n4/08.pdf>. http:// dx.doi.org/10.1590/S0034-89101988000400008.

HOLMES, Stephen; SUNSTEIN, Cass R. The cost of rights: why liberty depends on taxes. New York: W. W. Norton \& Company, 1999.

INSTITUTO BRASILEIRO DE GEOGRAFIA E ESTATÍSTICA - IBGE. Projeção da População do Brasil por sexo e idade: 2000-2060. Disponível em: <https://ww2.ibge.gov.br/ home/estatistica/populacao/projecao_da_populacao/2013/default_tab.shtm>. Acesso em: 15 maio 2018.

INSTITUTO RUI BARBOSA. Índice de efetividade da gestão municipal. Portal IEGM Brasil. Disponível em: <http://iegm.irbcontas.org.br/index.php>. Acesso em: 23 maio 2018.

PINTO, Élida G. Financiamento dos direitos à saúde e à educação. São Paulo: Fórum, 2015.

; FLEURY, Sônia. Custeio do direito à saúde: em busca da mesma proteção constitucional conquistada pelo direito à educação. Revista de Direito Sanitário, São Paulo, v. 12, n. 3, p. 54-80, mar./jun. 2012. Disponível em: <http://www.revistas.usp.br/rdisan/article/ view/55693/59109>. 10.11606/issn.2316-9044.v13i1p54-80.

PIOLA, Sérgio F. et al. Financiamento público da saúde: uma história à procura de rumo. Rio de Janeiro: Instituto de Pesquisa Econômica Aplicada, 2013. (Texto para discussão n. 1846).

SARLET, Ingo W. Direitos sociais: o problema de sua proteção contra o poder de reforma na Constituição de 1988. In: PIOVESAN, Flávia; GARCIA, Maria. (Orgs.). Direitos econômicos, sociais, culturais e ambientais. São Paulo: Revista dos Tribunais, 2008. p. 737-773. (Coleção doutrinas essenciais - direitos humanos; v. 3).

. Os direitos fundamentais sociais na Constituição de 1988. In: PIOVESAN, Flávia; GARCIA, Maria (Orgs.). Direitos econômicos, sociais, culturais e ambientais. São Paulo: Revista dos Tribunais, 2008. p. 639-675. (Coleção doutrinas essenciais - direitos humanos; v. 3). 
SCHEFFER, Mario C.; AITH, Fernando Mussa. A. O sistema de saúde brasileiro. In: Martins, Milton de Arruda et al. (Orgs.). Clínica médica. São Paulo: Manole, 2016. v. 1, p. 355-365.

VIANA, Ana L. D’Ávila; LIMA, Luciana D. de; FERREIRA, Maria P. Condicionantes estruturais da regionalização na saúde: tipologia dos Colegiados de Gestão Regional. Ciência e Saúde Coletiva, Rio de Janeiro, v. 15, n. 5, p. 2317-2326, 2010. Disponível em: <http://www.scielo. br/pdf/csc/v15n5/v15n5a07.pdf>. http://dx.doi.org/10.1590/S1413-81232010000500007.

VIEIRA, Fabiola S.; BENEVIDES, Rodrigo P. de S. e. Os impactos do novo regime fiscal para o financiamento do sistema único de saúde e para a efetivação do direito à saúde no Brasil. Brasília-DF: Instituto de Pesquisa Econômica Aplicada, 2016. (Nota técnica n. 28). Disponível em: <http://www.ipea.gov.br/portal/images/stories/PDFs/nota_tecnica/160920_nt_28_disoc. pdf $>$. Acesso em: 23 maio 2018.

WORLD BANK. World Bank national accounts data, and OECD National Accounts data files: GDP (current US\$). Disponível em: <https://data.worldbank.org/indicator/NY.GDP.MKTP. $\mathrm{CD}>$. Acesso em: 16 maio 2018.

WORLD HEALTH ORGANIZATION - WHO. Global Health Observatory data repository. Disponível em: <http://apps.who.int/gho/data/node.main.HEALTHFINANCING?lang=en>. Acesso em: 15 maio 2018.

$\mathrm{XU}, \mathrm{Ke}$ et al. New perspectives on global health spending for universal health coverage: global report. Geneva: World Health Organization, 2018. (Working paper WHO/HIS/HGF/HF n. 18.2). Disponível em: <http://apps.who.int/iris/bitstream/handle/10665/259632/WHOHIS-HGF-HFWorkingPaper-17.10-eng.pdf?sequence=1>. Acesso em: 23 maio 2018.

Donato Volkers Moutinho - Doutorando em Direito Econômico, Financeiro e Tributário na Faculdade de Direito da Universidade de São Paulo (USP); especialista em Direito Público pela Escola Superior de Advocacia da Ordem dos Advogados do Brasil Seção Espírito Santo (OAB-ES); bacharel em Direito e em Engenharia Elétrica pela Universidade Federal do Espírito Santo (UFES). Auditor de Controle Externo no Tribunal de Contas do Estado do Espírito Santo (TCE-ES). Vitória/ES, Brasil.E-mail: donatovolkers@gmail.com

Sueli Gandolfi Dallari - Doutora, mestre e livre-docente em Saúde Pública pela Universidade de São Paulo (FSP/USP); pós-doutora em Direito Médico pela Université de Paris XII (França); pós-doutora em Saúde Pública pela Columbia University (Estados Unidos). Professora Titular na FSP/USP; advogada. São Paulo/SP, Brasil. 